\title{
Studies on Slurry Design Fundamentals for Advanced CMP Applications CMP
}

\author{
G.B. Basim ${ }^{\mathrm{a}}$, A. Karagoz ${ }^{\mathrm{a}}$, Z. Ozdemir ${ }^{\mathrm{a}}$, I.U. Vakarelski ${ }^{\mathrm{b}}$, L. Chen ${ }^{\mathrm{b}}$ \\ ${ }^{a}$ Department of Mechanical Engineering, Ozyegin University, Istanbul 34794, Turkey \\ ${ }^{\mathrm{b}}$ Department of Physical Sciences and Engineering, King Abdullah University of Science \\ and Technology, Thuwal 23955, Saudi Arabia
}

\begin{abstract}
New developments and device performance requirements in microelectronics industry add to the challenges in chemical mechanical planarization (CMP) process. One of the recently introduced materials is germanium which enables improved performance through better channel mobility in shallow trench isolation (STI) applications. This paper reports on the slurry design alternatives for Ge CMP with surfactant mediation to improve on the silica/germanium selectivity using colloidal silica slurry. In addition to the standard CMP tests to evaluate the material removal rates, atomic force microscopy (AFM) based wear tests were also conducted to evaluate single particle-surface interaction of the polishing system. Furthermore, nature of the surface oxide film of germanium was studied through contact angle measurements and surface roughness tested by AFM. It was observed that the CMP selectivity of the silica/germanium system and defectivity control were possible with a reasonable material removal rate value by using self-assembled structures of cationic surfactants.
\end{abstract}

\section{Introduction}

Control of the Si-based CMOS devices in microelectronics industry has been limited with the continued device scaling introducing new materials with improved performances. Germanium is used to increase channel mobility of the deep channel metal oxide field effect transistors. Surface of germanium is typically very rough due to its epitaxial growth into the trenches after STI. A CMP application is needed to planarize Ge surface for enabling device fabrication (1).

CMP has been a critical process for semiconductor manufacturing enabling global planarization and selectivity through slurry formulations to accomplish multi-layer metallization. One of the most challenging aspects of the CMP process, particularly in applications like STI is the difference in relative removal rates of the surfaces polished when the interface is reached. Utilization of surface active agents became a common practice to achieve selectivity as well as provide slurry particle stability for defectivity control (2). In this study, slurry design requirements were investigated for Ge CMP through utilization of surfactant systems where they create self-assembled cohesive structures above their critical micelle concentrations (CMC). It has been shown in earlier investigations that the self-assembled structures of the twelve carbon chain CTAB 
surfactant (dodecyltrimethylammoniumbromide) effectively stabilized the silica-silica polishing system (3). Similar surfactants were evaluated to improve the selectivity on the Ge/Silica system earlier with affective suppression of the Ge dissolution. It was concluded that good planarization may be possible at $\mathrm{pH} 8$ using $0.1 \mathrm{mM}$ CTAB (16 carbon chain) with sufficient removal rates and minimized dissolution of germanium (4). Utilizing the self-assembled structures of the cationic surfactant, it was observed that the selectivity of the silica/germanium system and defectivity control were possible with a reasonable material removal rate value obtained during CMP.

\section{Experimental}

Germanium wafers with 2" diameter and $400 \mu \mathrm{m}$ Ge thickness obtained from University Wafer were cut to $46 \times 28 \mathrm{~mm}$ coupons for the CMP testing. CMP was conducted on a desktop Tegrapol-31 polisher by using SubaIV-IC1000 stacked polishing pad and silica slurry at $3 \mathrm{wt} \%$ loading and $100 \mathrm{~nm}$ particle size. $\mathrm{H}_{2} \mathrm{O}_{2}$ was added from a separate slurry feeder at $1 \mathrm{wt} \%$ concentration during CMP. $\mathrm{C}_{12} \mathrm{TAB}$ surfactant was used at twice $\mathrm{CMC}$ concentration $(32 \mathrm{mM})$ to provide self-assembled surfactant structures in the slurry. Slurry $\mathrm{pH}$ values were adjusted by $\mathrm{KOH}$ and $\mathrm{HNO}_{3}$. Polishing tests were conducted at $70 \mathrm{~N}$ downforce which is equivalent to a 7.88 psi pressure on the used sample size and with $150 \mathrm{rpm}$ rotational velocity at $100 \mathrm{ml} / \mathrm{min}$ slurry flow rate.

In order to characterize the wafer surfaces pre and post polish, wettability measurements were conducted through angle tests. Initially wafers were dipped into the solutions prepared with oxidizer, surfactant and oxidizer and surfactant combination for five minutes. Post dipping, surfaces were cleaned in DI water in an ultrasonic bath and dried using $\mathrm{N}_{2}$ gas and stored in clean petri dishes in a desiccator. Contact angle measurements were taken using DI water droplets through sessile drop method with a KSV ATTENSION Theta Lite Optic Contact Angle Goniometer. Minimum three drops were measured on each sample. The drop images were stored by a camera and an image analysis system was utilized to calculate the contact angle $(\Theta)$ from the shape of the drops. Nanomagnetics Instruments atomic force microscope (AFM) was used to obtain the surface roughness values on the wafers pre and post CMP. $5 \mu \mathrm{m} \times 5 \mu \mathrm{m}$ scans were obtained on each sample on randomly selected locations using tapping mode, to protect the naturally formed oxide films from deformation during scanning. AFM wear tests were conducted as a fast technique to evaluate single-particle surface interaction in the described solutions by using rectangular cantilevers, $\mathrm{K}_{\mathrm{N}}=4.5 \mathrm{~N} / \mathrm{m}(\mathrm{NSC} 35 / \mathrm{Si} 3 \mathrm{~N} 4$, MikroMasch). A region of $1 \mu \mathrm{m}$ was continuously worn through the AFM tip as it made continuous lateral scans over a fixed position on the substrate surface using applied load $\mathrm{F}_{\mathrm{N}}$. Scan direction was changed to image the wear trace applying a minimum load. AFM image and cross section were used to estimate the wear depth (5). Due to the bubbling of the system, $\mathrm{H}_{2} \mathrm{O}_{2}$ could not be used for the wear rate testing.

\section{Results and Discussions}

Initial screening for the material removal rate responses of the $\mathrm{Ge} / \mathrm{SiO}_{2}$ system in the presence of $\mathrm{C}_{12} \mathrm{TAB}$ at $2 \mathrm{xCMC}$ were conducted by using $\mathrm{AFM}$ wear tests at solution $\mathrm{pH}$ values of 2, 6 and 11. Figure 1 illustrates the results of the wear responses of the germanium versus silica wear rates. It is clearly seen that the silica wear rate was negligible at $\mathrm{pH}$ values 2 and 11 which was reported in the earlier investigations and can be tuned through slurry ionic strength and surfactant chain length tuning (7). However, a 


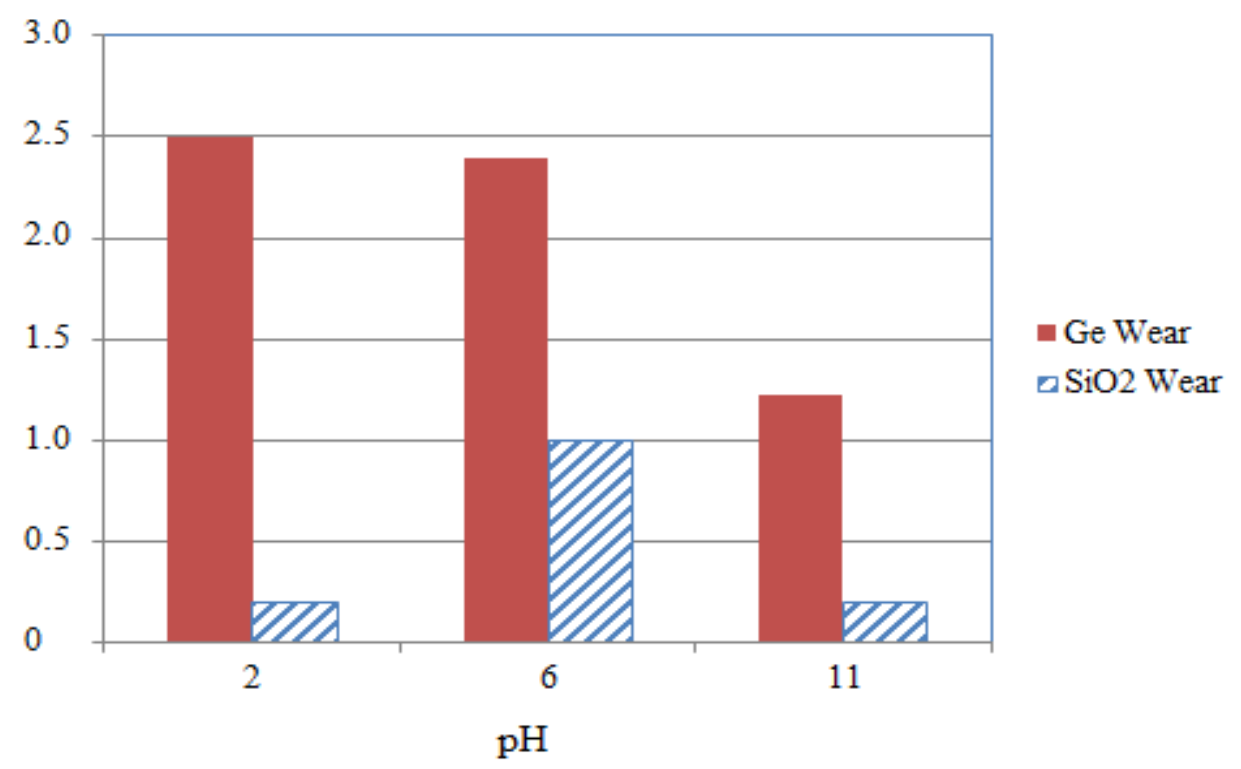

Figure 1. Wear rate responses of the germanium and silica wafers in the presence of $32 \mathrm{mM} \mathrm{C12TAB}$ surfactant aggregates at $\mathrm{pH} \mathrm{2,6}$ and 11.

reasonable wear was obtained for both germanium and silica at $\mathrm{pH}$. Therefore, the following tests were conducted at $\mathrm{pH} 6$ for $\mathrm{CMP}$ as well as for surface characterization.

In order to determine the changes in the nature of the germanium surfaces, contact angle and surface roughness tests were conducted on the wafers dipped into solutions prepared with 1 wt $\% \mathrm{H}_{2} \mathrm{O}_{2}, 32 \mathrm{mM} \mathrm{C} \mathrm{C}_{12} \mathrm{TAB}$ and the combination of both chemicals for five minutes. Germanium is a naturally hydrophobic mineral and hence it is expected to result in a high contact angle value with water with its native oxide on it (7). As it is summarized in Table 1, a contact angle of $\sim 72$ degrees was measured with the addition of $\mathrm{H}_{2} \mathrm{O}_{2}$ into the dipping solution. When the same test was conducted after dipping the surface into the surfactant only solution, the contact angle remained statistically the same yet a little lower at $\sim 64$ degrees. This can be attributed to the lower oxidation on the surface in the absence of the oxidizer. Surface oxidation tends to form surface oxide hillocks which were absent in the case of dipping the wafers into the surfactant only solution. as it was from the relatively lower RMS surface roughness values as well. When the germanium wafer was dipped into the combination of the surfactant and oxidizer, however, the measured contact angle and the surface roughness values changed significantly. Post treatment, the surfaces were observed to be rougher and more wettable. This result can be attributed to potential chemical adsorption of the surfactant molecules onto the germanium surface by complexing with the oxidizer. It was shown earlier that the nature of the polished surface is important for the material removal mechanisms during CMP applications $(8,9)$. Therefore, CMP tests were conducted next to determine the relative removal rates of germanium and silica and to evaluate surface quality. Figure 2 shows the CMP material removal rate responses for the three selected conditions. It is seen that for the oxidizer only condition germanium removal rate was almost three times of silica removal rate. Using the combination of surfactant and the oxidizer polishing, this ratio went down to $\sim 1.3$ suggesting that it may be possible to get 
Table 1. Contact angle and AFM surface roughness measurements for germanium surfaces dipped into solutions of $\mathrm{H}_{2} \mathrm{O}_{2}, 32 \mathrm{mM} \mathrm{C}_{12} \mathrm{TAB}$ and the combination of both chemicals for five minutes.

\begin{tabular}{|c|c|c|c|}
\hline$@$ pH 6 & $\begin{array}{c}\mathrm{H}_{2} \mathrm{O}_{2} \\
(1 \% \mathrm{wt}) \\
\end{array}$ & $32 \mathrm{mM} \mathrm{C} \mathrm{C}_{12} \mathrm{TAB}$ & $\begin{array}{c}\% 1 \mathrm{H}_{2} \mathrm{O}_{2} \\
32 \mathrm{mM} \mathrm{C} \mathrm{C}_{12} \mathrm{TAB} \\
\end{array}$ \\
\hline Contact Angle (Degrees) & $72.23 \pm 1.93$ & $64.31 \pm 5.11$ & $53.30 \pm 0.70$ \\
\hline RMS Surface Roughness (nm) & $2.78 \pm 0.08$ & $2.55 \pm 0.4$ & $3.37 \pm 0.78$ \\
\hline
\end{tabular}

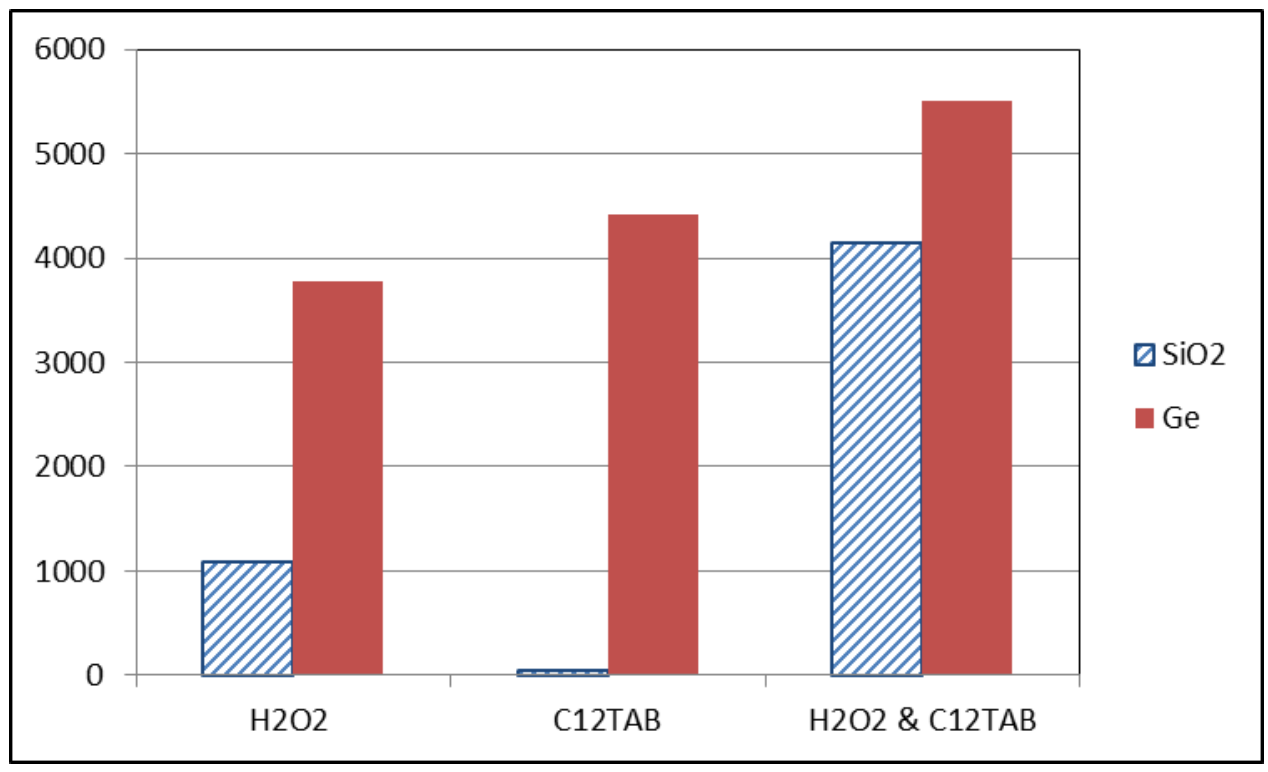

Figure 2. CMP material removal rate responses for the germanium versus silica surfaces with only oxidizer $\left(\mathrm{H}_{2} \mathrm{O}_{2}-1 \mathrm{wt} \%\right)$, only surfactant $\mathrm{C}_{12} \mathrm{TAB}(32 \mathrm{mM})$ and mixture of both.

a similar removal rate of silica and germanium when the interface is hit during CMP. However, the target is to get the silica removal faster for better device performance (10), which can be improved further with similar approaches.

One other important aspect of surfactant addition is to help improve the surface quality. Addition of the self-assembled surfactant structures are known to help better stabilize the CMP slurries and hence improve surface quality in aggressive slurry conditions (3). Therefore, in addition to the improvements in the slurry selectivity, it is also expected that the surface quality will be better when the $\mathrm{C}_{12} \mathrm{TAB}$ is added into the slurries at above the CMC concentrations. Indeed, when the polishing was conducted 
with only oxidizer addition, the RMS surface roughness was measured to be $29 \pm 20 \mathrm{~nm}$ which reduced to $14 \pm 8 \mathrm{~nm}$ with the addition of the $\mathrm{C}_{12} \mathrm{TAB}$ into the solution in the presence of the oxidizer.

\section{Summary}

While the self-assembled surfactant structures help improve slurry stability, they may retard the material removal rates by inhibiting the particle surface interactions. The results of this study have shown that in the presence of hydrogen peroxide in the slurry, removal rates are mainly affected by the oxidizer. These preliminary results also show that the surface quality and the selectivity of the $\mathrm{Ge} / \mathrm{SiO}_{2}$ systems can be improved by addition of cationic surfactant aggregates. Further improvements can be achieved by tuning the concentration of the oxidizer and surfactant type or chain length and tuning the ionic strength of the system.

\section{Acknowledgments}

The authors would like to acknowledge the support from the European Union FP7 Marie Curie IRG grant on the project entitled "Nano-Scale Protective Oxide Films for Semiconductor Applications \& Beyond".

\section{References}

1. J.B. Strength, N.K. Matovu, S.P. Penta, S.V. Babu. Journal of The Electrochemical Society, 158 (11), p.61 (2007).

2. G.B. Basim. In Engineered Particulate Systems for Chemical Mechanical Planarization, Lambert Academic Publishing, Saarbrucken, Germany (2011).

3. G.B. Basim, I.U. Vakarelski, B.M. Moudgil. Journal of Colloid and Interface Science, 263, p. 506 (2003).

4. J.B. Matovu, N.K. Penta, S. Peddeti, S.V. Babu. Journal of The Electrochemical Society, 158 (11), p. H1152 (2011).

5. I.U. Vakarelski, N. Teramoto, C.E. McNamee, J.O. Marston, K. Higashitani. Langmuir, 28 (46), p.16072 (2012).

6. I.U. Vakarelski, S.C. Brown, G.B. Basim, Y.I. Rabinovich, B.M. Moudgil, B.M. ACS Appl. Mater. Interfaces, 10, p. 397 (2010)

7. J. Drxylama, J. Lekki, Powder Technology, 52, p. 251 (1987).

8. G.B. Basim. ECS Transactions, 25 (7), p. 315-326 (2009).

9. G.B. Basim, A. Karagoz, Z. Ozdemir. MRS Proceedings, Vol. 1428 (2012) DOI: 10.1557/opl.2012.1361.

10. S. Peddeti, P. Ong, L.H.A. Leunissen, S.V. Babu. Microelectronics Engineering, 93, p.61 (2012) 